\title{
Numerical Simulation Study of the Influence of Flue Gases Recirculated on $\mathrm{NO}_{\mathrm{x}}$ Emissions
}

\author{
Yunkai Yue, Aiqin Li, Zhe Zhao, Jiadi Ma \\ Beijing Institute of Petro-chemical Technology, Beijing 102617,China
}

\begin{abstract}
Flue gas recirculation is considered to be one of the most promising and cost-effective $\mathrm{NO}_{\mathrm{x}}$ reduction strategies for combustion systems. Therefore, it has great scientific and practical significances to investigate the flue gas recirculation process. Fluent was used to perform a numerical flue gas recirculation simulation on natural gas combustion in a burner, revealing the relationship between $\mathrm{NO}_{\mathrm{x}}$ emission and circulation ratio, circulation temperature, and circulation locations. The following conclusions were drawn: the $\mathrm{NO}_{\mathrm{x}}$ generated with gas recirculation on is less than when there is no gas recirculation; the lower the gas circulation temperature, the less the $\mathrm{NO}_{\mathrm{x}}$; when the circulation is $25 \%$, the $\mathrm{NO}_{\mathrm{x}}$ generated is low; less $\mathrm{NO}_{\mathrm{x}}$ is generated if the gas is firstly mixed with the air before combustion.
\end{abstract}

\section{Introduction}

Combustion processes are typically considered as ones of the main factors responsible for the emission to the atmosphere of important air pollutants, such as $\mathrm{NO}_{\mathrm{x}}, \mathrm{SO}_{2}$ and particulate matter. $\mathrm{NO}_{\mathrm{x}}$ is produced during the combustion process in a high temperature region and is known as a source of major air pollution that generates ozone when it reacts with sunlight; $\mathrm{NO}_{\mathrm{x}}$ also causes respiratory diseases ${ }^{[1-3]}$. Flue gas recirculation (FGR) is an interesting technique for reduction of nitrogen oxide $\left(\mathrm{NO}_{\mathrm{x}}\right)$ emissions that can be applied to boilers or internal combustion engines. This technique includes recirculation of part of flue gases back to the combustion chamber; it may be responsible for various effects on combustion, pollutant formation and emissions.

CFD is an analysis of systems involving fluid flow by means of computer-based simulations. These systems may also involve heat transfer and associated phenomena such as chemical reactions. CFD simulations are based upon a numerical solution of basic equations of the fluid dynamics, conservation of mass, momentum, and energy, together with mathematical sub-models. The equations can be solved in three-dimensions. Comprehensive modelling of combustion in general requires simulation turbulent fluid dynamics, chemical kinetics as well as their interactions.

FLUENT 15 is a general-purpose CFD code, which is based on finite volumes, and the region of interest is divided into small sub-regions called control volumes. The equations are discretized and solved iteratively, providing the value of each variable (velocity,

The mathematical model is based on the numerical solution of the time-averaged equations governing conservation of mass, momentum and energy and transport equations for scalars describing turbulence and combustion.

3-D Navier-Stokes equations, the energy conservation equation, and the species conservation equations are discretized by the finite volume method. The discretization method is a second order upwind scheme, and the SIMPLE algorithm is adopted for the coupling of pressure and velocity. For the calculation, the standard $k$ e eddy viscosity-diffusivity model is used to describe the temperature, mass fractions etc.) for each control volume throughout the calculation domain.

$\mathrm{NO}_{\mathrm{x}}$ emissions from natural gas combustion are studied, with the objective to demonstrate the applicability of stationary computational fluid dynamics simulations, including a detailed representation of gas phase chemistry, to a burner fired reactor using natural gas as a fuel.

\section{Mathematical model}

In this study, gas burner BT350GRF chosen is shown in Figure 1; its power is in the range of $500 \mathrm{~kW}-924 \mathrm{~kW}$, and power supply pressure is between 40 and $300 \mathrm{mbar}$, power supply is $380 \mathrm{v} / \mathrm{Hz}$, motor $7.5 \mathrm{~kW}$, its size is 1500 $\mathrm{x} 1080 \mathrm{x} 800 \mathrm{~mm}$, and weight is $330 \mathrm{~kg}$, with flame size $356 \times 275 \mathrm{~mm}$.

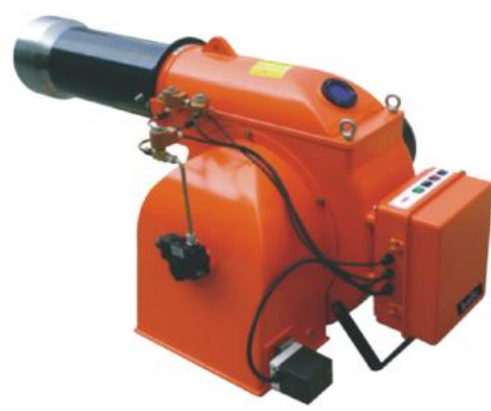

Figure 1. Structure graphing of gas burner BT350GRF

fluid flow considering the air and fuel velocities supplied from the nozzles. The parabolic flows of the fuel and air are injected into ambient air at a standard temperature and pressure. The following pressure outlet conditions are applied to the exhaust outlet, which has the same diameter as that of the ventilation tube, zero temperature gradients, species mole fractions, and axial and radial velocities. For the wall of the chamber, no-slip conditions and zero species mole fraction gradients are applied, and convective heat transfer is applied at the wall boundary. To determine convergence of the solution, the residual in the energy conservation equation is defined as being less 
than $1 \times 10^{8}$ and the residuals in other equations are less than $1 \times 10^{5}$.

\subsection{Species Transport Equations}

We have chosen to solve conservation equations for ANSYS FLUENT predicts the local mass fraction of each species, $Y_{i}$, through the solution of a convection-diffusion equation for the $i$ th species. This conservation equation takes the following general form:

$$
\frac{\partial}{\partial t}\left(\rho Y_{i}\right)+\nabla \cdot\left(\rho \bar{v} Y_{i}\right)=-\nabla \cdot \bar{J}_{i}+R_{i}+S_{i}
$$

Where $R_{i}$ is the net rate of production of species by chemical reaction (described later in this section) and $S_{i}$ is the rate of creation by addition from the dispersed phase plus any user-defined source. An equation of this form will be solved for $N-1$ species where $N$ is the total number of fluid phase chemical species present in the system. Since the mass fraction of the species must be equal to unity, the $N$ th mass fraction is determined as one minus the sum of the $N-1$ mass fractions. To minimize numerical errors, the $N$ th species should be selected as that species with the overall largest mass fraction, such as $N_{2}$ when the oxidizer is air.

\subsection{Mass Diffusion in Turbulent Flows}

In turbulent flows, ANSYS FLUENT computes the mass diffusion in the following form:

$$
\bar{J}_{i}=-\left(\rho D_{i, m}+\frac{\mu_{t}}{S c_{t}}\right) \nabla Y_{i}-D_{T, i} \frac{\nabla T}{T}
$$

Where $S c_{t}$ is the turbulent Schmidt number ( $\mu_{t} / \rho D_{t}$ where $\mu_{t}$ is the turbulent viscosity and $D_{t}$ is the turbulent diffusivity). The default $S c_{t}$ is 0.7 . Note that turbulent diffusion generally overwhelms laminar diffusion, and the specification of detailed laminar diffusion properties in turbulent flows is generally not necessary.

We will use the generalized eddy-dissipation model to analyze the natural gas-air combustion system. The combustion will be modeled using a global one-step reaction mechanism, assuming complete conversion of the fuel to $\mathrm{CO}_{2}$ and $\mathrm{H}_{2} \mathrm{O}$. The reaction equation is

$$
\mathrm{CH}_{4}+2 \mathrm{O}_{2} \rightarrow \mathrm{CO}_{2}+2 \mathrm{H}_{2} \mathrm{O}
$$

The reaction equation is defined in terms of stoichiometric coefficients, formation enthalpies, and parameters that control the reaction rate. The reaction rate is determined assuming that turbulent mixing is the rate limiting process, with the turbulence-chemistry interaction modeled using the eddy-dissipation model.

\subsection{NOx Prediction}

The formation of $\mathrm{NO}_{\mathrm{x}}$ can be attributed to four distinct chemical kinetic processes ${ }^{[4]}$ : thermal $\mathrm{NO}_{\mathrm{x}}$ formation, prompt $\mathrm{NO}_{\mathrm{x}}$ formation, fuel $\mathrm{NO}_{\mathrm{x}}$ formation, and intermediate $\mathrm{N}_{2} \mathrm{O}$. Thermal $\mathrm{NO}_{\mathrm{x}}$ is formed by the oxidation of atmospheric nitrogen present in the combustion air. Prompt $\mathrm{NO}_{\mathrm{x}}$ is produced by high-speed reactions at the flame front. We will calculate the formation of both thermal and prompt NOx.

\section{Effect of flue gas recirculation on $\mathrm{NO}_{\mathrm{x}}$}

\subsection{Effect of circulation ratio on $\mathrm{NO}_{\mathrm{x}}$}

We will compare the temperature of the burner with the flue gas recirculation and that of the gas recirculation.

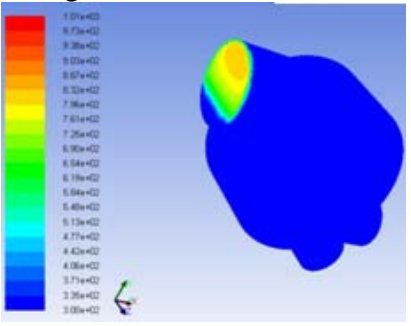

Contours temperature without flue gas recirculation

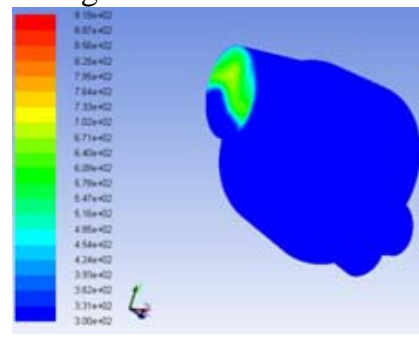

Contours temperature of flue gas recirculation
Figure 2. contours of temperature flue gas recirculation on outlet

As a result, it can be known from Figure 2, that compared with the use of flue gas recirculation, there is a certain reduction in temperature, which is due to the low temperature of the flue gas into the burner. It is necessary to reduce the temperature of the burner, and due to the addition of the flue gas, the $\mathrm{O}_{2}$ volume fraction of the burner and the volume fraction of $\mathrm{CO}_{2}$ can be reduced. The number increases, thereby reducing the generation of $\mathrm{NO}_{\mathrm{x}}$.

\subsection{Effect of circulation ratio on $\mathrm{No}_{\mathrm{x}}$}

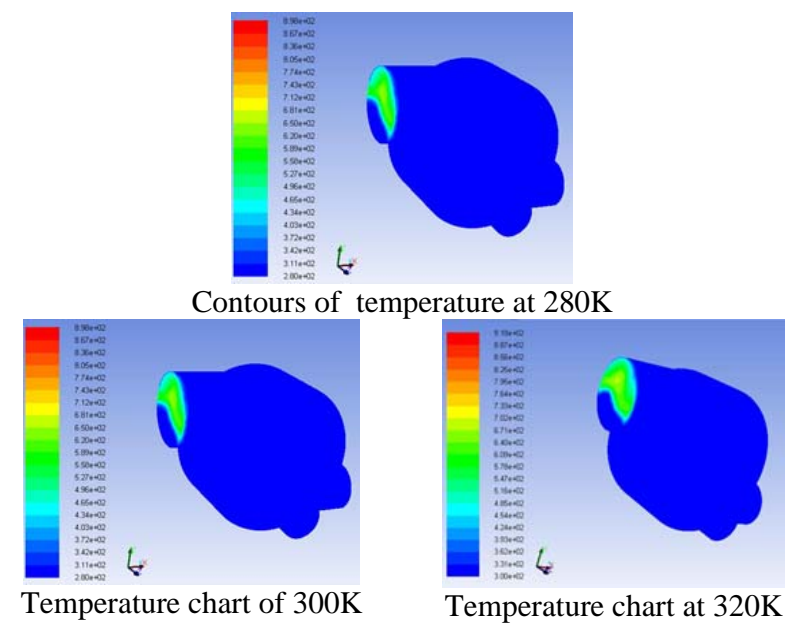

Figure 3. At different temperature chart gas inlet, burner, gas export 
At the $280 \mathrm{~K}$

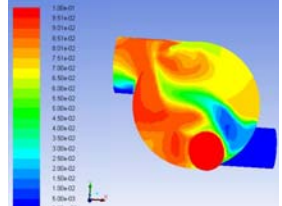

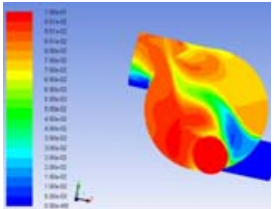

At the $300 \mathrm{~K}$

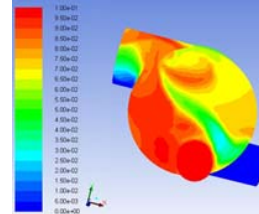

At the $320 \mathrm{~K}$
Figure 4. $\mathrm{NO}_{\mathrm{x}}$ distribution at different temperature

According to Figure 3 and Figure 4, a different circulating temperature $\mathrm{NO}_{\mathrm{x}}$ is in the flue gas inlet, the burner, and the content of the flue gas exports, as shown in figure 5.

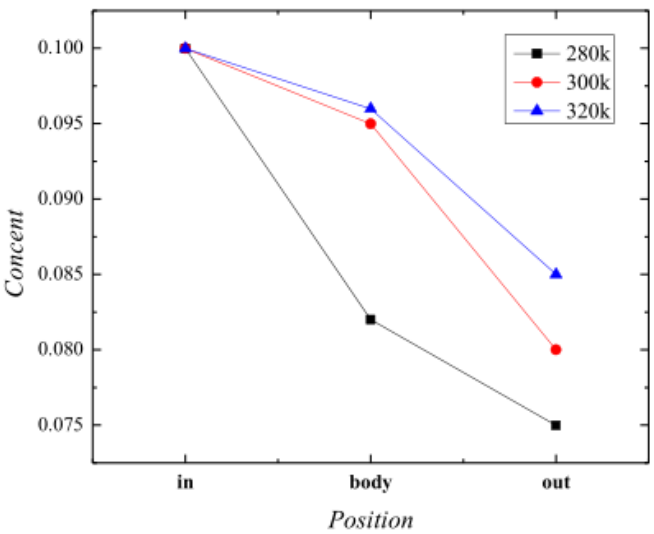

Figure 5. NOx of different circulating temperature in the flue gas inlet, burner, gas export content diagram

As shown in Figures 3-5, it is known that the lower the cycling temperature, the less $\mathrm{NO}_{\mathrm{x}}$. This is because when the low temperature of the flue gas enters the burner, the overall temperature of the burner is reduced to a certain extent. Then the production of $\mathrm{NO}_{\mathrm{x}} \cdot \mathrm{CO}_{2}$ is reduced. Under the same conditions, the circulating rate is different, comparing the results of the burner temperature contours, the velocity vector chart and $\mathrm{NO}_{\mathrm{x}}$ distribution.
Contours of temperature at the circulation rate $15 \%$

Figure 6. Contours of temperature at different circulation rat

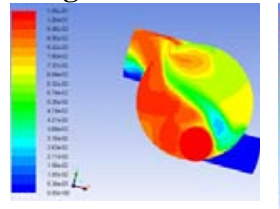

At the circulation rate $15 \%$

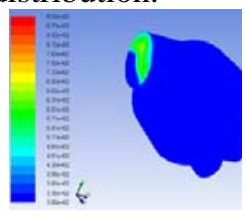

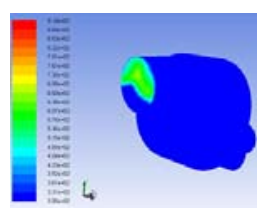

Contours of temperature at the circulation rate $25 \%$

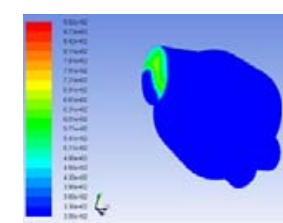

Contours of temperature at the circulation rate $35 \%$

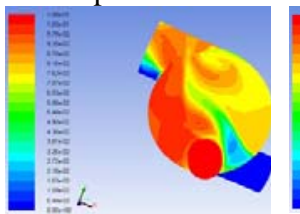

At the circulation rate25\%

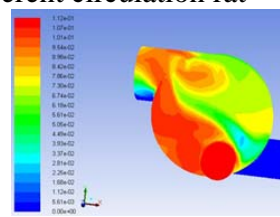

At the circulation rate $35 \%$
Figure 7. Contours of $\mathrm{NO}_{\mathrm{x}}$ distribution at different circulation rate

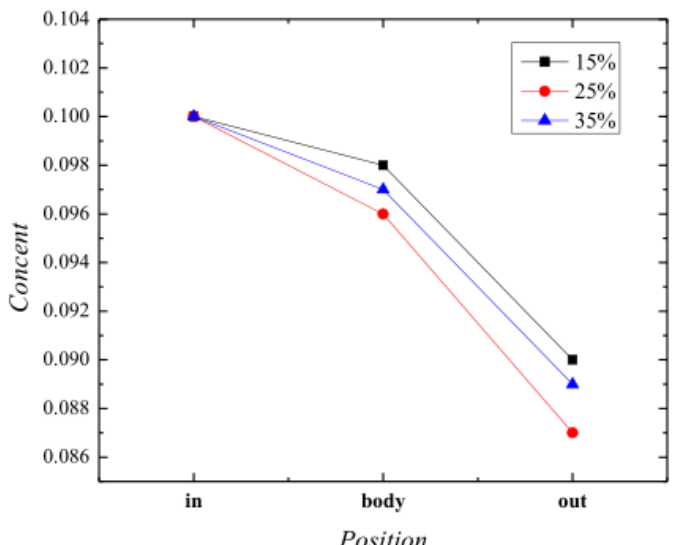

Figure 8. Content of $\mathrm{NO}_{\mathrm{x}}$ in different circulating rate at the flue

As shown in Figures 6 to $8, \mathrm{NO}_{\mathrm{x}}$ is decreased and then increased with the increase of flue gas recirculation rate, at the flue gas recirculation rate $25 \% . \mathrm{NO}_{\mathrm{x}}$ is relatively small, and it can be found that the temperature is lower at the gas recirculation rate of $25 \%$. This is due to a certain extent of flue gas recirculation to reduce the temperature in the burner. In order to inhibit the formation of thermal $\mathrm{NO}_{\mathrm{x}}$, and to increase flue gas recirculation, the flue gas velocity increases, so that the smoke in the flame of residence time is reduced. This also inhibits the generation of the normal $\mathrm{NO}_{\mathrm{x}}$. The change of firing conditions will affect the formation of fuel $\mathrm{NO}_{\mathrm{x}}$. Compared with the non-use of flue gas recirculation, the temperature of the burner can be reduced by using the flue gas recirculation. This is due to the low temperature of flue gas into the burner. It is necessary to reduce the temperature of the burner, due to the circulation of flue gas. With the addition of $\mathrm{NO}_{\mathrm{x}}$, the volume fraction of $\mathrm{O}_{2}$ decreases and the volume fraction of $\mathrm{CO}_{2}$ increases and then decreases. Numerical simulation of $\mathrm{NO}_{\mathrm{x}}$ pollution emission is reduced by flue gas recirculation.

\subsection{The effect of cyclic position on $\mathrm{NO}_{x}$}

On the same conditions, the circulation position is different, comparing the results of the burner temperature contours, the velocity vector chart and $\mathrm{NO}_{\mathrm{x}}$ distribution.

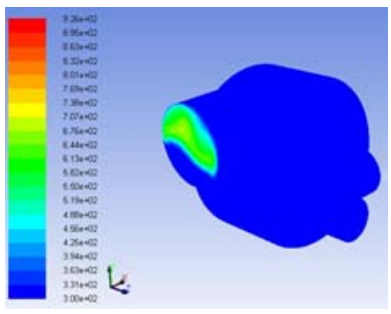

Contours of natural gas, air, flue gas at identical inlet temperature

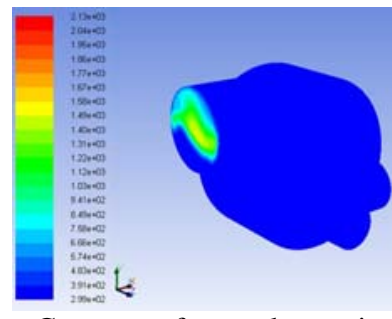

Contours of natural gas, air, flue gas at different inlet temperature
Figure 9. contours of natural gas, air, flue gas at inlet temperature 


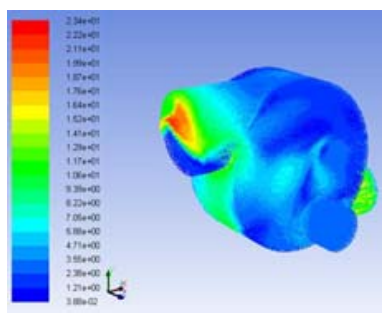
flue gas at identical inlet velocity
Contours of natural gas, air,

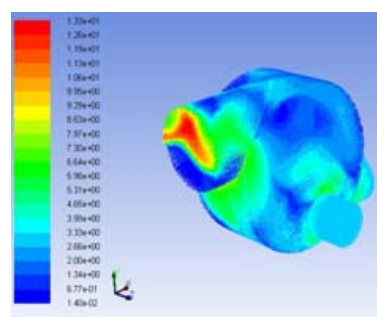

Contours of natural gas, air ,flue gas at different inlet velocity
Figure 10. Contours of natural gas, air, flue gas at identical inlet velocity

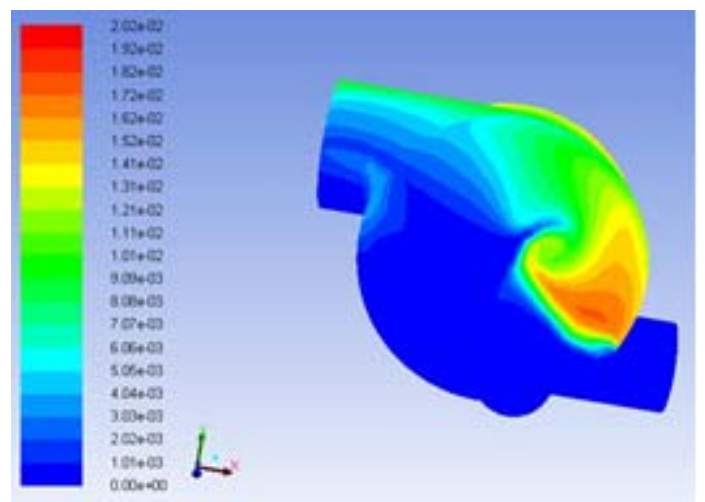

Figure 11. Natural gas air flue gas with inlet NOx distribution

As shown in Figure 9-11, when the outlet temperature is relative to the same inlet of natural gas, air and gas are lower. The relatively slow rate of export, to a certain extent, inhibits the formation of $\mathrm{NO}_{\mathrm{x}}$, so that the amount of $\mathrm{NO}_{\mathrm{x}}$ is reduced.

\section{Conclusion}

In this paper, effects of flue gas recirculation ratio and fuel types on $\mathrm{NO}_{\mathrm{x}}$ are investigated, and the effects of air preheating temperature and oxygen concentration on $\mathrm{NO}_{\mathrm{x}}$ have also been discussed. According to the predicted results, flue gas internal recirculation is an effective method for reduction of $\mathrm{NO}_{\mathrm{x}}$, and $\mathrm{NO}_{\mathrm{x}}$ is rapidly decreased with an increase in the recirculation ratio. The influence of air preheating temperature and oxygen concentration on $\mathrm{NO}_{\mathrm{x}}$ emission is negligible when the flue gas recirculation ratio is high enough. The temperature of the circulation is $280 \mathrm{~K}, 300 \mathrm{~K}, 320 \mathrm{~K}$, the cyclic rate is $15 \%, 25 \%$ and $35 \%$ respectively. And under the same conditions in the case of different circulation of the 4 types of discussions, we can get the following conclusions: 1) The $\mathrm{NO}_{\mathrm{x}}$ produced by the use of flue gas recirculation is less than that of non-use of flue gas recirculation for the low temperature flue gas returns to the gas supply system, and the gas mixture is reduced. The concentration of oxygen, heat absorber, the combustion temperature become too high, thereby inhibiting the generation of nitrogen oxides. 2) The lower the temperature of the flue gas is, the lower the $\mathrm{NO}_{\mathrm{x}}$ is. When the flue gas enters the burner, the overall temperature of the burner is reduced to some extent, and the combustion is suppressed. And the production of $\mathrm{NO}_{\mathrm{x}}$ is reduced. 3) At the circulation rate of $25 \%, \mathrm{NO}_{\mathrm{x}}$ is less. When the flue gas recirculation rate is higher, the combustion will be unstable, and the heat loss will increase, and the $\mathrm{NO}_{\mathrm{x}}$ yield will be affected. 4) The gas and air mixed with the first mixture will produce less $\mathrm{NO}_{\mathrm{x}}$.

With the previous 4 conclusions, we can clearly know that flue gas recirculation is important for $\mathrm{NO}_{\mathrm{x}}$ production and influence. The principle of flue gas recirculation is simple and easy to understand, the device is easy to install, and the price is not very high; therefore, in natural gas, gas pollution reduction has an important role. Flue gas recirculation is an important way to reduce $\mathrm{NO}_{\mathrm{x}}$, and it is also an important way to reduce pollutants in the future. If in the future we should carry out a deeper research, the research results will be used to achieve the greatest possible reduction of emissions of pollutants.

\section{References}

[1] Gao X, Duan F, Lim SC, Yip MS. $\mathrm{NO}_{\mathrm{x}}$ formation in hydrogen-methane turbulent diffusion flame under the moderate or intense low-oxygen dilution conditions. Energy 59:559-69. (2013)

[2] Chen Z, Li Z, Zhu Q, Jing J. Gas/particle flow and combustion characteristics and $\mathrm{NO}_{\mathrm{x}}$ emissions of a new swirl burner. Energy 36:709-23.( 2011)

[3] Navi MN. Theoretical investigation of engine thermal efficiency, adiabatic flame temperature, $\mathrm{NO}_{\mathrm{x}}$ emission and combustion related parameters for different oxygenated fuels. Appl Therm Eng 30:83944. (2010)

[4] Ansys, Inc. Ansys fluent theory guide. PA U.S.A.: Canonsburg; 2012 